\title{
A case of allergic bronchopulmonary aspergillosis successfully treated with mepolizumab
}

Takeshi Terashima* ${ }^{*}$, Taro Shinozaki, Eri Iwami, Takahiro Nakajima and Tatsu Matsuzaki

\begin{abstract}
Background: Allergic bronchopulmonary aspergillosis (ABPA) is an allergic pulmonary disease comprising a complex hypersensitivity reaction to Aspergillus fumigatus. Clinical features of ABPA are wheezing, mucoid impaction, and pulmonary infiltrates. Oral corticosteroids and anti-fungal agents are standard therapy for ABPA, but long-term use of systemic corticosteroids often causes serious side effects.

Case presentation: A 64-year-old woman was diagnosed with ABPA based on a history of bronchial asthma (from 40 years of age), elevated total lgE, the presence of serum precipitating antibodies and elevated specific lgE antibody to A. fumigatus, and pulmonary infiltration. Bronchoscopy showed eosinophilic mucoid impaction. Systemic corticosteroid therapy was initiated, and her symptoms disappeared. Peripheral eosinophilia and pulmonary infiltration recurred five months after cessation of corticosteroid treatment. Systemic corticosteroids were re-initiated and itraconazole was added as an anti-fungal agent. The patient was free of corticosteroids, aside from treatment with a short course of systemic corticosteroids for asthma exacerbation, and clinically stable with itraconazole and asthma treatments for 3 years. In 2017, she experienced significant deterioration. Laboratory examination revealed marked eosinophilia (3017/ $\mu \mathrm{L})$ and a chest computed tomography $(\mathrm{CT})$ scan demonstrated pulmonary infiltration in the left upper lobe and mucoid impaction in both lower lobes. The patient was treated with high-dose inhaled corticosteroid/long-acting beta-agonist, a long-acting muscarinic antagonist, a leukotriene receptor antagonist, and theophylline; spirometry revealed a forced expiratory volume in $1 \mathrm{~s}\left(\mathrm{FEV}_{1}\right)$ of $1.01 \mathrm{~L}$. An uncontrolled asthma state was indicated by an Asthma Control Test (ACT) score of 18. Mepolizumab, $100 \mathrm{mg}$ every 4 weeks, was initiated for the treatment of severe bronchial asthma with ABPA exacerbation. Bronchial asthma symptoms dramatically improved, and ACT score increased to 24, by 4 weeks after mepolizumab treatment. Peripheral eosinophil count decreased to $174 / \mu \mathrm{L}$. Spirometry revealed improvement of lung function (FEV $1: 1.28 \mathrm{~L}$ ). A chest CT scan demonstrated the disappearance of pulmonary infiltration and mucoid impaction.
\end{abstract}

Conclusions: To our knowledge, this is the first case of ABPA to be treated with mepolizumab. Dramatic improvements were observed in symptoms, lung function, peripheral eosinophil counts, and chest images. Mepolizumab could serve as an alternative treatment with the potential to provide a systemic corticosteroidsparing effect.

Keywords: Mepolizumab, Allergic bronchopulmonary aspergillosis, Bronchial asthma, Eosinophilia

\footnotetext{
* Correspondence: terasima@tdc.ac.jp

Department of Respiratory Medicine, Tokyo Dental College Ichikawa General

Hospital, 5-11-13, Sugano, Ichikawa, Chiba 272-0824, Japan
}

(c) The Author(s). 2018 Open Access This article is distributed under the terms of the Creative Commons Attribution 4.0 International License (http://creativecommons.org/licenses/by/4.0/), which permits unrestricted use, distribution, and reproduction in any medium, provided you give appropriate credit to the original author(s) and the source, provide a link to the Creative Commons license, and indicate if changes were made. The Creative Commons Public Domain Dedication waiver (http://creativecommons.org/publicdomain/zero/1.0/) applies to the data made available in this article, unless otherwise stated. 


\section{Background}

Allergic bronchopulmonary aspergillosis (ABPA) is an allergic pulmonary disease with a complex hypersensitivity reaction to Aspergillus fumigatus. Clinical characteristics of ABPA include recurrent asthma exacerbations; chest images of affected patients reveal mucoid impaction, pulmonary eosinophilic infiltrates, and bronchiectasis. Allergic immune reactions can be observed, such as peripheral eosinophilia and elevated total IgE, as well as the presence of serum precipitating antibodies and elevated specific IgE antibody to $A$. fumigatus $[1,2]$. Because ABPA is caused by a hypersensitivity reaction to bronchial colonization by $A$. fumigatus, standard therapy comprises a combination of systemic corticosteroids (to attenuate allergic inflammation) and anti-fungal agents (to reduce the fungal load). Serious side effects of corticosteroids are a notable risk in patients undergoing long-term treatment. In this report, we describe a case of severe bronchial asthma with ABPA that was successfully treated with mepolizumab, a recombinant anti-IL-5 antibody.

\section{Case presentation}

A 64-year-old woman was diagnosed with bronchial asthma at 40 years of age. Initially, her symptoms were mild and controlled with a moderate dose of inhaled corticosteroid (ICS) and a short-acting beta-agonist. She reported a medical history of eosinophilic rhinitis. At 60 years of age, she experienced frequent wheezing exertion; spirometry revealed forced expiratory volume in $1 \mathrm{~s}$ $\left(\mathrm{FEV}_{1}\right) /$ forced vital capacity (FVC) of $62.6 \%, \mathrm{FEV}_{1}$ of $0.92 \mathrm{~L}$, and peak expiratory flow of $3.37 \mathrm{~L} / \mathrm{s}$. She was diagnosed with severe bronchial asthma and treated with an ICS/long-acting beta-agonist (LABA), a long-acting muscarinic antagonist (LAMA), a leukotriene receptor antagonist (LTRA), and theophylline. The patient exhibited purulent sputum, despite these medications, for 3 months and was referred to our hospital in 2013 because of persistent fever that had lasted 2 weeks. Laboratory examination showed a white blood cell count of $12,700 / \mu \mathrm{L}$ (27\% eosinophils), C-reactive protein level of $11.79 \mathrm{mg} / \mathrm{dL}$, serum IgE level of $3400 \mathrm{IU} / \mathrm{mL}$, and positive Aspergillus-specific IgE (6.24 UA/mL). Serum proteinase-3 anti-neutrophil cytoplasmic antibody (ANCA) and myeloperoxidase-ANCA were negative (< $1.0 \mathrm{U} / \mathrm{mL}$ ). Precipitating antibody to Aspergillus was positive by the technique of Ouchterlony. A chest radiograph showed opacity in the right lower field; a computed tomography (CT) scan showed infiltration in the right middle and lower lobes, as well as mucoid impaction in both lower lobes (Fig. 1). Bronchoscopy revealed a mucoid impaction in the right middle lobe bronchus (Fig. 2); the differential specimen count obtained by bronchial washing from the right middle lobe was

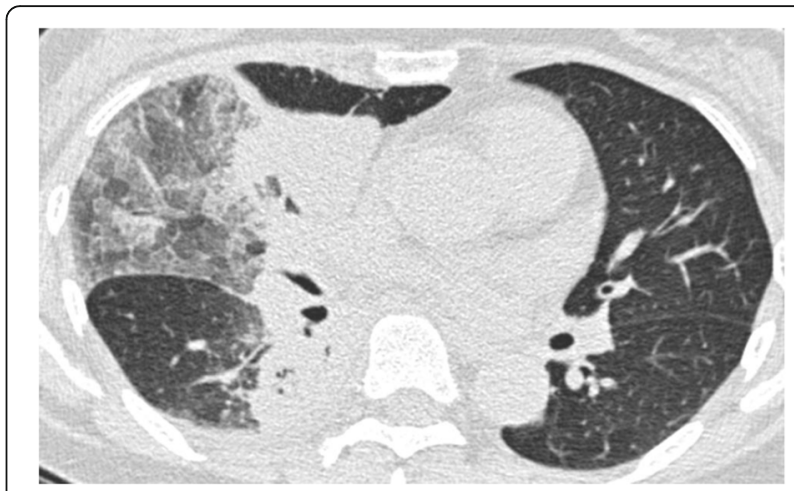

Fig. 1 Computed tomography image of the chest showing infiltration in the right middle and lower lobes

composed of $38 \%$ eosinophils. Notably, the bronchial washing culture yielded no bacteria or fungus. The patient was diagnosed with ABPA based on the history of bronchial asthma, elevated total IgE, the presence of serum precipitating antibody and elevated specific IgE antibody to A. fumigatus, and pulmonary infiltration. Systemic corticosteroid therapy (prednisone $30 \mathrm{mg} /$ day) was initiated, and the patient's symptoms dissipated. The corticosteroids were gradually tapered, then discontinued after 3 months. The patient developed "moon face" as a consequence of corticosteroid treatment; peripheral eosinophilia and pulmonary infiltration appeared again, 5 months after the cessation of corticosteroid treatment. Systemic corticosteroids (prednisone $10 \mathrm{mg} /$ day) were re-initiated, and itraconazole (200 $\mathrm{mg} /$ day) was added as

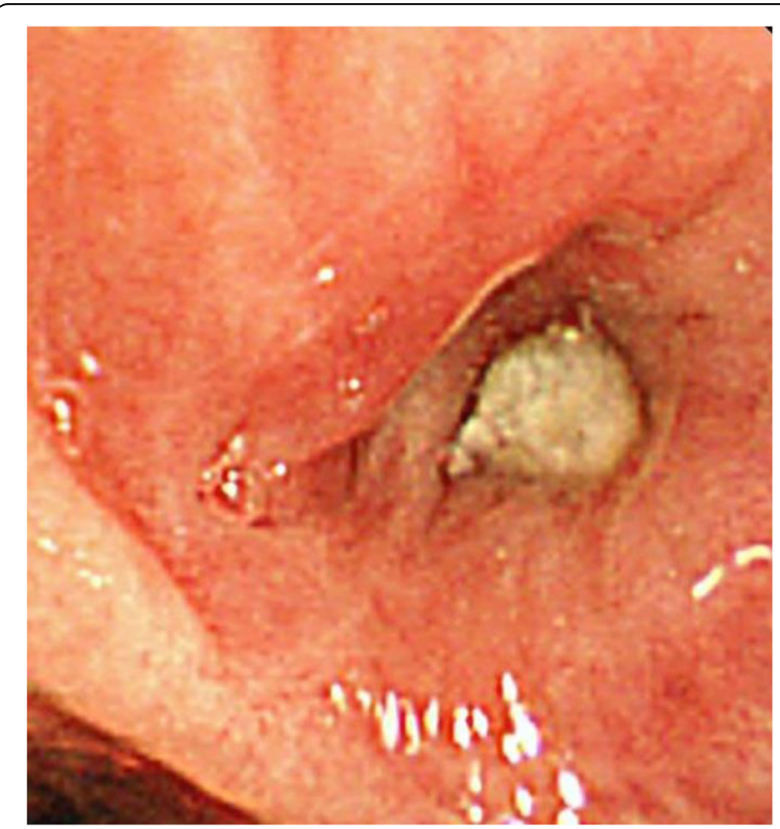

Fig. 2 Bronchoscopic findings showing mucus plugging within the right middle lobe bronchus 
an anti-fungal agent. Systemic corticosteroid treatment was again tapered and discontinued after 4 weeks. The patient was free of corticosteroids, aside from treatment with a short course of systemic corticosteroids for asthma exacerbation, and clinically stable with itraconazole and asthma treatments for 3 years.

In 2017, the patient experienced significant deterioration. She complained of wheezing, productive cough, and dyspnea on effort. Laboratory examination revealed marked peripheral eosinophilia $(3017 / \mu \mathrm{L})$ and a chest CT scan demonstrated pulmonary infiltration in the left upper lobe, as well as mucoid impaction in both lower lobes (Fig. 3). The patient was treated with high-dose ICS/LABA, LAMA, LTRA, and theophylline; spirometry showed severe airway obstruction (FEV 1 /FVC: 66.9\%; $\mathrm{FEV}_{1}$ : $\left.1.01 \mathrm{~L}\right)$. An uncontrolled asthma state was indicated by an Asthma Control Test (ACT) score of 18. Mepolizumab (100 mg every 4 weeks) was initiated for the treatment of severe bronchial asthma with ABPA exacerbation. Bronchial asthma symptoms were dramatically improved, and ACT score was increased to 24 at 4 weeks after mepolizumab treatment. Peripheral eosinophil count decreased from 3017/ $\mu \mathrm{L}$ to $230 / \mu \mathrm{L}$ and $174 / \mu \mathrm{L}, 1$ and 4 weeks after mepolizumab, respectively. Spirometry showed improvement of lung function $\left(\mathrm{FEV}_{1} / \mathrm{FVC}\right.$ : 69.8\%; $\mathrm{FEV}_{1}$ : $1.25 \mathrm{~L}$ after 1 week; $\mathrm{FEV}_{1}$ / FVC: $69.2 \%, \mathrm{FEV}_{1}$ : $1.28 \mathrm{~L}$ after 4 weeks). The serum level of IgE did not change after mepolizumab. A chest CT scan demonstrated the disappearance of pulmonary infiltration and mucoid impaction (Fig. 3).

\section{Discussion and conclusions}

To our knowledge, this is the first case of ABPA to be treated with mepolizumab. Dramatic improvements were observed in symptoms, lung function, peripheral eosinophil counts, and chest images.

Our patient was diagnosed with ABPA because the observed clinical, radiologic, and laboratory findings met essential criteria for ABPA that were proposed in 2013, which include: 1) predisposing conditions: asthma or cystic fibrosis; 2) obligatory criteria: total baseline serum IgE $>1000 \mathrm{IU} / \mathrm{mL}$, as well as positive immediate hypersensitivity skin test or elevated specific IgE to A. fumigatus; 3 ) supportive criteria: eosinophilia $>500$ cells $/ \mu \mathrm{L}$, serum precipitating or IgG antibodies to A. fumigatus, and consistent radiologic opacities [1]. The radiologic features include transient (consolidation, nodules, and tram-track or gloved-finger appearance) or permanent (bronchiectasis or fibrosis) pulmonary opacities. Although persistent fever, which was seen in our case, is not a common symptom of ABPA, fever is included as one of the symptoms of ABPA [1, 3]. Differential diagnoses in our case included eosinophilic pneumonia and eosinophilic granulomatosis with polyangiitis. The predominant patterns of CT findings in acute eosinophilic pneumonia are consolidation and/or ground-glass opacity, frequently accompanied by interlobular septal thickening [4]. Positive IgE against $A$. fumigatus and mucoid impaction (as documented by imaging and bronchoscopy) suggested ABPA, rather than acute eosinophilic pneumonia, in our case. The absence of extrathoracic manifestation and negative ANCA excluded the possibility of eosinophilic granulomatosis with polyangiitis.

ABPA is a severe type of allergic asthma that occurs in approximately $10 \%$ of patients with severe asthma. Although a combination of systemic corticosteroids and antifungal agents is a standard therapy, there is a risk of serious side effects with long-term use of systemic corticosteroids, such as "moon face," immunosuppression, diabetes, gastric ulcer, and osteoporosis. Omalizumab, a monoclonal antibody against IgE, has been used in ABPA treatment [5]. Reviews of ABPA cases, including 17 bronchial asthma cases that were treated with omalizumab, have shown beneficial effects such as reduced symptoms, decreased exacerbation rates, and corticosteroid-sparing effects [6]. The dose of omalizumab is determined by a patient's baseline total IgE level and body weight. The upper limit of the total IgE level is $1500 \mathrm{IU} / \mathrm{mL}$; omalizumab can be administered up to a maximum dose of $600 \mathrm{mg}$ every 2 weeks [7]. Notably, many patients with ABPA exceed the current dosing parameters of omalizumab because of their high total IgE levels, which is a limitation of omalizumab therapy [8].

Mepolizumab is a monoclonal antibody against interleukin-5, a cytokine that releases eosinophils from bone marrow and activates their functions [9]. Mepolizumab has been shown to reduce the frequency of asthma exacerbations in patients with severe eosinophilic asthma [10]. Moreover, mepolizumab exhibited a corticosteroid-sparing effect in eosinophilic asthma patients who require daily systemic corticosteroids [11]. A post hoc analysis showed that mepolizumab was effective for patients, regardless of prior history of omalizumab use; moreover, most patients in the prior omalizumab use subgroup reported that omalizumab was ineffective [12]. Total IgE level at the start of therapy does not affect the efficacy or adverse effects of mepolizumab, and mepolizumab is recommended as one of the therapeutic options in cases of severe eosinophilic asthma with total IgE > $1500 \mathrm{IU} / \mathrm{mL}$ [13].

The mechanisms underlying ABPA exacerbation are complex. The increased secretion of interleukin- 4 and interleukin-5 from peripheral cells from patients with ABPA suggests that TH2 inflammation contributes to the pathogenesis of ABPA [14]. Notably, elevated levels of IgE and specific antibody against $A$. fumigatus suggested that clinical benefits may result from treatment with omalizumab; additionally, a marked eosinophilia in peripheral blood and bronchial washing suggested that beneficial effects may result from treatment with mepolizumab. The 


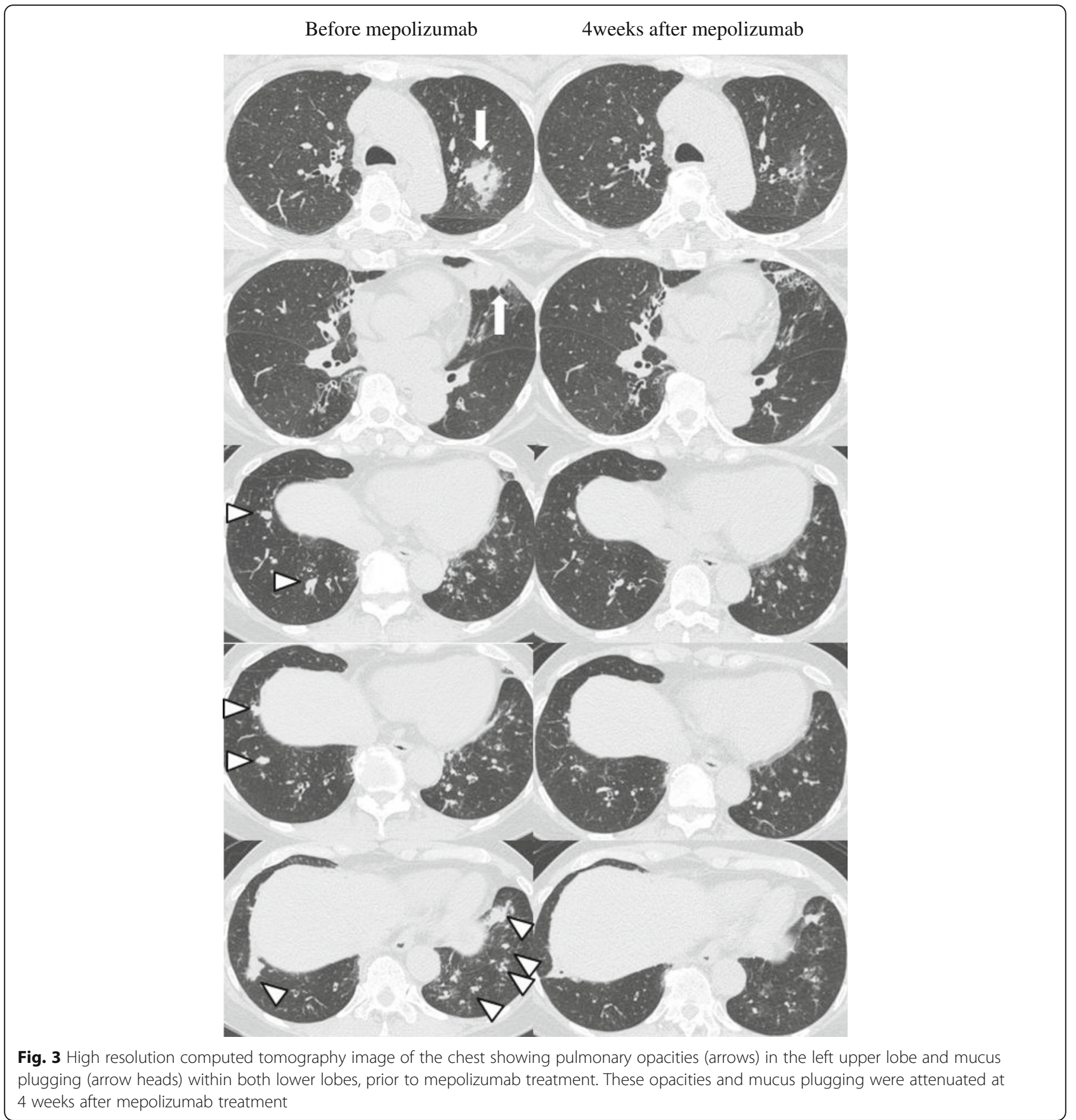

synergistic effects of omalizumab and mepolizumab have been reported in a patient with severe and steroiddependent ABPA [15]. Our case showed that a single dose of mepolizumab alone induced a 6-point increase in ACT score, 270-mL increase in $\mathrm{FEV}_{1}$, and a 94\% reduction in peripheral eosinophil counts; moreover, it attenuated pulmonary infiltration and mucoid impaction. An ACT score of $\leq 19$ indicates uncontrolled asthma and a 3-point change in ACT score is clinically significant [16]. The improvement of lung function in our case appears to be dramatic, compared with the study of patients with severe eosinophilic asthma, in which the mean increase in $\mathrm{FEV}_{1}$ was $100 \mathrm{~mL}$ after mepolizumab therapy [10].

It has been reported that an attempt to discontinue omalizumab resulted in exacerbation, which was resolved with reinstitution of omalizumab [6]. In our case, we have maintained mepolizumab as treatment for severe asthma with ABPA. Further observation is necessary to determine the optimal period of mepolizumab treatment. 
In this report, we described a case of severe bronchial asthma with ABPA that was successfully treated with mepolizumab. Mepolizumab could serve as an alternative treatment with the potential for systemic corticosteroidsparing effects. Double-blind, placebo-controlled trials are necessary to establish the efficacy and safety of this novel therapeutic intervention for ABPA.

\section{Abbreviations}

ABPA: Allergic bronchopulmonary aspergillosis; ACT: Asthma control test; ANCA: Anti-neutrophil cytoplasmic antibody; CT: Computed tomography; $\mathrm{FEV}_{1}$ : Forced expiratory volume in $1 \mathrm{~s}$; FVC: Forced vital capacity; ICS: Inhaled corticosteroid; LABA: Long-acting beta-agonist; LAMA: Long-acting muscarinic antagonist; LTRA: Leukotriene receptor antagonist

\section{Acknowledgements}

Not applicable.

\section{Funding}

The authors declare that no funding was received for this study.

\section{Availability of data and materials}

All data generated or analyzed during this study are included in this published article.

\section{Authors' contributions}

$\Pi$ Tा contributed to decision of treatment, collecting clinical data, data analysis, and writing the manuscript. TS, El, TN, and TM contributed to the interpretation of clinical data and chest images. All authors have read and approved the final manuscript.

\section{Ethics approval and consent to participate}

Not applicable.

\section{Consent for publication}

Written informed consent was obtained from the patient for publication of this case report and accompanying images. A copy of the written consent is available for review by the Editor of this journal.

\section{Competing interests}

The authors declare that they have no competing interests.

\section{Publisher's Note}

Springer Nature remains neutral with regard to jurisdictional claims in published maps and institutional affiliations.

Received: 29 December 2017 Accepted: 16 March 2018

Published online: 27 March 2018

\section{References}

1. Agarwal R, Chakrabarti A, Shah A, Gupta D, Meis JF, Guleria R, et al. Allergic bronchopulmonary aspergillosis: review of literature and proposal of new diagnostic and classification criteria. Clin Exp Allergy. 2013;43:850-73.

2. Knutsen AP. Allergic bronchopulmonary aspergillosis in asthma. Expert Rev Clin Immunol. 2017;13:11-4.

3. Shah A, Panjabi C. Allergic bronchopulmonary aspergillosis: a perplexing clinical entity. Allergy Asthma Immunol Res. 2016:8:282-97.

4. Yeon JJ, Kim K-I, Im JS, Chang HL, Ki NL, Ki NK, et al. Eosinophilic lung diseases: a clinical, radiologic, and pathologic overview. Radiographics. 2007; 27:617-37.

5. Van Der Ent CK, Hoekstra H, Rijkers GT. Successful treatment of allergic bronchopulmonary aspergillosis with recombinant anti-lgE antibody. Thorax. 2007:62:276-7.

6. Li J-X, Fan L-C, Li M-H, Cao W-J, Xu J-F. Beneficial effects of omalizumab therapy in allergic bronchopulmonary aspergillosis: a synthesis review of published literature. Respir Med. 2017;122:33-42.

7. Jaffe JS, Massanari M. In response to dosing omalizumab in allergic asthma. J Allergy Clin Immunol. 2007;119:255-6.
8. Agarwal R, Gupta D, Aggarwal AN, Saxena AK, Chakrabarti A, Jindal SK. Clinical significance of hyperattenuating mucoid impaction in allergic bronchopulmonary aspergillosis: an analysis of 155 patients. Chest. 2007; 132:1183-90.

9. Sanderson CJ. Interleukin-5, eosinophils, and disease. Blood. 1992;79:3101-9.

10. Ortega HG, Liu MC, Pavord ID, Brusselle GG, FitzGerald JM, Chetta A, et al. Mepolizumab treatment in patients with severe eosinophilic asthma. New Engl J Med. 2014;371:1198-207.

11. Bel EH, Wenzel SE, Thompson PJ, Prazma CM, Keene ON, Yancey SW, et al Oral glucocorticoid-sparing effect of mepolizumab in eosinophilic asthma. New Engl J Med. 2014;371:1189-97.

12. Magnan A, Bourdin A, Prazma CM, Albers FC, Price RG, Yancey SW, et al. Treatment response with mepolizumab in severe eosinophilic asthma patients with previous omalizumab treatment. Allergy Eur J Allergy Clin Immunol. 2016:71:1335-44.

13. Menzella F, Galeone C, Bertolini F, Castagnetti C, Facciolongo N. Innovative treatments for severe refractory asthma: how to choose the right option for the right patient? J Asthma Allerg. 2017;10:237.

14. Rathore VB, Johnson B, Fink JN, Kelly KJ, Greenberger PA, Kurup VP. T cell proliferation and cytokine secretion to $T$ cell epitopes of asp $f 2$ in ABPA patients. Clin Immunol. 2001;100:228-35.

15. Itman MC, Lenington J, Bronson S, Ayars AG. Combination omalizumab and mepolizumab therapy for refractory allergic bronchopulmonary aspergillosis. J Allergy Clin Immunol Pract. 2017;5:1137-9.

16. Schatz M, Kosinski M, Yarlas AS, Hanlon J, Watson ME, Jhingran P. The minimally important difference of the asthma control test. J Allergy Clin Immunol. 2009;124:719-23.
Submit your next manuscript to BioMed Central and we will help you at every step:

- We accept pre-submission inquiries

- Our selector tool helps you to find the most relevant journal

- We provide round the clock customer support

- Convenient online submission

- Thorough peer review

- Inclusion in PubMed and all major indexing services

- Maximum visibility for your research

Submit your manuscript at www.biomedcentral.com/submit
Ciomed Central 